\title{
INTRODUCTION TO THE SPECIAL EDITION ON EXPERT EVIDENCE
}

\author{
JASON M CHIN*AND CAITLIN GOSS ${ }^{\dagger}$
}

We are very pleased to introduce this special issue of The University of Queensland Law Journal on expert evidence. As many readers will be aware, expert evidence remains a contentious issue both in Australia and abroad. Questions have been raised, for instance, about the reliability of many traditional fields of expert evidence, biases experts may carry with them into court, and the risk of trials transforming into battles of experts. ${ }^{1}$ We hope that this special issue contributes to the ongoing discussion.

Many people and groups were integral in making this issue possible. First, we would like to thank the UQ Law, Science and Technology program, which funded and enabled the colloquia that led to this special issue. ${ }^{2}$ As to those events, we would like to thank the Supreme Court of Queensland for hosting them and the many speakers and discussants that generously volunteered their time: the Hon Justice Peter Applegarth, the Hon Justice Soraya Ryan, Kaye Ballantyne, Emma Cunliffe, Ben Dighton, Rachel Dioso-Villa, David Hamer, Kathryn McMillan QC, Mehera San Roque and Rachel Searston. We also thank the TC Beirne School of Law, and Rick Bigwood, Iain Field and the UQLJ, for their generous support.

This special issue begins with David Hamer and Gary Edmond's 'Forensic Science Evidence, Wrongful Convictions and Adversarial Process', which helps frame many of the issues herein. ${ }^{3}$ This article delves into recent post-conviction appeals, and in doing so highlights many of the challenges that forensic science (which is typically adduced by the prosecution) presents in adversarial systems.

\footnotetext{
Sydney Law School; Institute for Globally Distributed Open Research and Education ('IGDORE'). TC Beirne School of Law, The University of Queensland.

See Gary Edmond, 'Forensic Science Evidence and the Conditions for Rational (Jury) Evaluation' (2015) 39(1) Melbourne University Law Review 77; Lisa Dufraimont, 'Regulating Unreliable Evidence: Can Evidence Rules Guide Juries and Prevent Wrongful Convictions?' (2008) 33 Queen's Law Journal 261.

Jason $M$ Chin, 'UQ Expert Evidence Colloquium 1', Truth in Evidence (Web Page) $<$ https://www.jasonmchin.com/jason-chin-evidence-blog/2018/9/5/uq-expert-evidencecolloquium-aug-30-2018>; Jason M Chin, 'UQ Expert Evidence Colloquium 2', Truth in Evidence (Web Page) <https://www.jasonmchin.com/jason-chin-evidence-blog/2019/2/18/uq-expertevidence-colloquium-pt-2-february-12-2019>.

David Hamer and Gary Edmond, 'Forensic Science Evidence, Wrongful Convictions and the Adversarial Process' (2019) 38(2) University of Queensland Law Journal 185.
} 
Another such challenge is highlighted in Searston and Chin's article, which suggests that some forms of forensic expertise are primarily subjective, intuitive judgements of the practitioner, which makes them difficult to explain and crossexamine. ${ }^{4}$ In the following article, Smith and Thompson argue that an important step for many forensic practices - and one that may assuage some concerns about them being subjective and intuitive - is testing experts' claims. ${ }^{5}$ Smith and Thompson find that many fields still have work to do in delineating testable claims. McKimmie and colleagues then discuss another fundamental issue in expert evidence: gender biases that may impact how the trier of fact assesses the evidence. ${ }^{6}$ They find some evidence for such bias in an original empirical study.

The remainder of the special issue goes on to discuss specific topics of expert evidence. Gary Edmond explores the history of fingerprint analysis in Australian courts and finds - troublingly - that it has almost never been challenged on epistemic grounds. ${ }^{7}$ Monds and colleagues discuss the complex and fraught issue of police serving as 'experts' when assessing whether an individual is intoxicated through exposure to drugs or alcohol. ${ }^{8}$ They find that legislation governing such practices is underdeveloped, and that further research is needed into police training and how police go about making judgements of intoxication. Finally, McMillan and Pokarier consider social scientific expert evidence and tzhe various ways in which such evidence is introduced into court. ${ }^{9}$

Rachel A Searston and Jason M Chin, 'The Legal and Scientific Challenge of Black Box Expertise' (2019) 38(2) University of Queensland Law Journal 237.

Chloe A Smith and Matthew B Thompson, 'Performance Claims in Forensic Science Expert Opinion Evidence' (2019) 38(2) University of Queensland Law Journal 261.

Blake M McKimmie et al, 'The Impact of Gender-Role Congruence on the Persuasiveness of Expert Testimony' (2019) 38(2) University of Queensland Law Journal 279.

Gary Edmond, 'Latent Science: A History of Challenges to Fingerprint Evidence in Australia' (2019) 38(2) University of Queensland Law Journal 301.

Lauren A Monds et al, 'Police as Experts in the Detection of Alcohol and Other Drug Intoxication: A Review of the Scientific Evidence within the Australian Legal Context' (2019) 38(2) University of Queensland Law Journal 367.

Kathryn McMillan and Nicholas Pokarier, 'Beyond Common Knowledge: Reviewing the Use of Social Science Evidence in Australian Courts' (2019) 38(1) University of Queensland Law Journal 389. 